\title{
Can you trust the good guys? Trust within and between groups with different missions
}

\author{
Fehrler, Sebastian ; Kosfeld, Michael
}

\begin{abstract}
Non-governmental organizations and other non-profit organizations attract workers who strongly identify themselves with their missions. We study whether these "good guys" are more trustworthy, and how such pronounced group identities affect trust and trustworthiness within the groups and towards out-groups. We find that subjects who strongly identify themselves with a non-profit mission are more trustworthy in a minimal group setting but also harshly discriminate against out-groups when subjects are grouped by the missions they identify themselves with.
\end{abstract}

DOI: https://doi.org/10.1016/j.econlet.2013.09.007

Posted at the Zurich Open Repository and Archive, University of Zurich

ZORA URL: https://doi.org/10.5167/uzh-86507

Journal Article

Originally published at:

Fehrler, Sebastian; Kosfeld, Michael (2013). Can you trust the good guys? Trust within and between groups with different missions. Economics Letters, 121(3):400-404.

DOI: https://doi.org/10.1016/j.econlet.2013.09.007 
IZA DP No. 7411

Can You Trust the Good Guys? Trust Within and Between Groups with Different Missions

Sebastian Fehrler

Michael Kosfeld

May 2013 


\title{
Can You Trust the Good Guys? Trust Within and Between Groups with Different Missions
}

\author{
Sebastian Fehrler \\ University of Zurich and IZA
}

\author{
Michael Kosfeld \\ Goethe University Frankfurt, \\ CEPR, CESifo and IZA
}

\section{Discussion Paper No. 7411 \\ May 2013}

\author{
IZA \\ P.O. Box 7240 \\ 53072 Bonn \\ Germany \\ Phone: +49-228-3894-0 \\ Fax: +49-228-3894-180 \\ E-mail: iza@iza.org
}

\begin{abstract}
Any opinions expressed here are those of the author(s) and not those of IZA. Research published in this series may include views on policy, but the institute itself takes no institutional policy positions. The IZA research network is committed to the IZA Guiding Principles of Research Integrity.

The Institute for the Study of Labor (IZA) in Bonn is a local and virtual international research center and a place of communication between science, politics and business. IZA is an independent nonprofit organization supported by Deutsche Post Foundation. The center is associated with the University of Bonn and offers a stimulating research environment through its international network, workshops and conferences, data service, project support, research visits and doctoral program. IZA engages in (i) original and internationally competitive research in all fields of labor economics, (ii) development of policy concepts, and (iii) dissemination of research results and concepts to the interested public.
\end{abstract}

IZA Discussion Papers often represent preliminary work and are circulated to encourage discussion. Citation of such a paper should account for its provisional character. A revised version may be available directly from the author. 


\section{ABSTRACT \\ Can You Trust the Good Guys? Trust Within and Between Groups with Different Missions}

NGOs and other non-profit organizations attract workers who strongly identify themselves with their missions. We study whether these "good guys" are more trustworthy and how such pronounced group identities affect trust and trustworthiness within the groups and toward outgroups. We find that subjects who strongly identify themselves with a non-profit mission are more trustworthy in a minimal group setting but also harshly discriminate against out-groups when subjects are grouped by the missions they identify themselves with.

JEL Classification: $\quad$ C72, C92, M51

Keywords: social identity theory, group identity, trust, trustworthiness, discrimination, organization

Corresponding author:

Sebastian Fehrler

University of Zurich

Affolternstrasse 56

$\mathrm{CH}-8050$ Zurich

Schweiz

E-mail: sebastian.fehrler@uzh.ch 


\section{Introduction}

Organizations have different missions. Particularly salient are missions in non-profit organizations who derive their raison d'être from their particular non-profit goals. In this study we analyze effects of such group identities on behavior directed toward in-group members and toward out-groups.

Several studies suggest that some workers strongly care about non-profit missions (e.g., Besley and Ghatak 2005, Delfgaauw and Dur 2007). In a lab experiment, Fehrler and Kosfeld (2012) find that roughly one third of the subjects forgo a higher wage and choose instead a contract under which they can generate a donation to a non-governmental organization (NGO). Sorting of types with different social preferences and the consequences for organizations have also been discussed in recent theoretical papers (e.g., Brekke and Nyborg 2010, Kosfeld and von Siemens 2011). Empirically Brekke, Hauge, Lind, and Nyborg (2011) show that sorting into groups with and without a non-profit mission leads to more cooperation within the first type of group in a public goods game, suggesting that sorting leads to groups with different social preferences (see also Lazear, Malmendier, and Weber 2012).

Another potentially important issue in this context, group identity, has, however, not received much attention. In-group favoritism and out-group discrimination are well known phenomena in social psychology. Even minimal group identities, induced by randomly labeling groups, can lead to intergroup discrimination. ${ }^{1}$ In recent years, also economists have begun to study the effects of group identities on social behavior (e.g., Charness, Rigotti, and Rustichini 2007, Ben-Ner, McCall, Stephane, and Wang 2009, Chen and Li 2009, Hargreaves Heap and Zizzo 2009, Tsutsui and Zizzo 2012). If group identities are strong and reflect differences in social preferences, stronger effects might be expected than in a minimal group setting.

We study trust and trustworthiness comparing treatments with groups with minimal group identities and with groups with pro-social identities. Group identities are induced by grouping participants according to their answers to two questions in a short questionnaire that participants had to fill in before the experiment. In the minimal group treatment subjects are grouped according to the question if they like one of the painters Paul Klee or Wassily Kandinski or if they like neither. In the mission treatment subjects are grouped according to the question if they identify themselves strongly with the goals of one of the NGOs, World Wildlife Fund (WWF) or Amnesty International (AI), or none of them.

We find that subjects who identify themselves strongly with an NGO (the "good guys") are significantly more trustworthy. This suggests that attracting such employees could have advantages for an organization beyond pure motivation effects. However, these subjects also strongly discriminate between the types of trustors and transfer back substantially more

\footnotetext{
${ }^{1}$ One of the earliest studies in this context is Tajfel, Billig, Bundy, and Flament (1971). See Brewer (1979) and Mullen, Brown, and Smith (1992) for reviews of the early literature.
} 
to trustors who also identify themselves with an NGO. The comparison with the minimal group treatment shows that the difference in the back transfers toward in- and out-groups is completely driven by negative discrimination of the out-group. These findings suggest that mismatches between worker and leadership missions or between the missions of different organizations could be detrimental for cooperation inside and between organizations. ${ }^{2}$

\section{Experimental Design}

In the beginning, before receiving instructions for the trust game, subjects are asked to fill in a short questionnaire on their computer screens. The questionnaire includes questions like "Do you do sports?", "Do you play an instrument?", and the question "Do you strongly identify yourself with the goals of one of the NGOs, Amnesty International or the WWF?". The last question is the one we use in our mission treatment. It has the following answer options: "WWF", "Amnesty International" and "None of the two". One option has to be checked and multiple answers are ruled out. In the minimal group treatment, we use a different question from the same questionnaire to form groups: "Do you like one of the painters: Paul Klee or Wassily Kandinski?" with answer options, "Klee", "Kandinsky" and "None of the two". With this treatment we relate to the classic social psychology study in this field by Tajfel et al. (1971) in which preferences about Klee and Kandinski are used as well to form "minimal" groups. The questionnaire is designed to give the subjects the impression that they take part in a small socioeconomic survey to make it unlikely that they expect that their answers play a role in the experiment.

After reading the instructions and a short comprehension quiz, subjects play a trust game (Berg, Dickhaut, and McCabe 1995) in which transfer choices are limited to 4 options. Half of the subjects are trustors the other half trustees. All recipients receive an initial endowment of 12 points. Trustors can transfer $0,4,8$ or 12 points to the trustee. The transfers are tripled. The trustees can then send back any integer amount of points from the points they dispose of back to the trustor.

Trustors and trustees can make their transfer decision in the investment game conditional on the type of the recipient, i.e., on the answer of their partner to the NGO question in the mission treatment and on the answer to the art question in the minimal group treatment. The strategy method is used. Trustors make three transfer decisions, one for each potential type of trustee. Trustees make twelve decisions, one for every possible type of trustor and received transfer. ${ }^{3}$ In addition to the transfer decisions, we ask the trustors about their

\footnotetext{
${ }^{2}$ The related problem of worker-leadership mission mismatches for worker motivation is discussed in Besley and Ghatak (2005).

${ }^{3}$ The use of the strategy method in an investment game has been shown to lead to lower trustworthiness as compared to the "direct response" method (Casari and Cason 2009). In the context of this experiment, this might lead to an attenuation of the effect of group identity on trustworthiness. Having subjects make transfers to the different groups of recipients appears natural when the goal is to study whether they discriminate
} 
beliefs regarding back transfers for all possible transfer levels and types of trustees. The answers to these questions have no influence on the pay-offs. After the transfers are made and the beliefs elicited, the experiment ends and the subjects are paid out.

One point in the trust game is worth CHF 0.8 (at the time of the experiment CHF 1 was worth USD 0.9). Overall, 190 subjects ( $52 \%$ female) participated in the experiment in the laboratory of the Department of Economics at the University of Zurich. ${ }^{4}$ On average the participants earned CHF 14.8 in addition to a show-up fee of CHF 10 and spent around 45 minutes in the lab.

\section{Results}

\subsection{Trustor Behaviour}

Figure 1 presents the expected back transfers from different types of trustees, i.e., beliefs about their trustworthiness. We see that trustors expect lower back transfers from subjects who do not strongly identify themselves with the goals of either NGO (henceforth called No-NGO types). Regressing expected back transfers from each group on the transfers (i.e., estimating linear fits for the three groups in Fig. 1) results in statistically significantly steeper slopes for WWF and AI than for No-NGO ( $\mathrm{p}<0.01$, F-Test, Regression (1), Table 2). ${ }^{5}$

Moreover, we see that the beliefs about back transfers from AI and WWF types are almost the same. Table 1 shows the transfer levels to the different types of trustees from the different types of trustors. The differences between the transfer levels reflect the beliefs about the back transfers. Even the No-NGO types transfer less to other No-NGO types than to AI or WWF types. For the No-NGO types, the differences of the transfer levels to the three trustee types are pairwise statistically different $(\mathrm{p}<0.05$, Wilcoxon rank sum test). For the other two groups the transfer level to No-NGO types is statistically different $(\mathrm{p}<0.05)$ to the transfer to the other two groups which themselves are not significantly different from each other $(\mathrm{p}>0.1)$. Transfers to No-NGO types are lower than to any other group. The NGO types receive, on average, $47 \%$ higher transfers than No-NGO types. The lower half of Table 1 shows the transfer levels in the minimal group treatment. Here, each type of trustor favors trustees with the same art preferences but there is no single group that is less trusted than all the other groups.

\subsection{Trustee Behavior}

In the analysis of trustee behavior we start by looking at the trustworthiness of the different NGO types in the minimal group treatment where they cannot condition their back transfer

between these groups.

${ }^{4}$ The treatments were programmed with zTree (Fischbacher 2007).

${ }^{5}$ This finding holds for all types of trustors (see models (2)-(4) in Table 2). 
Figure 1: Beliefs about the trustworthiness of different trustees

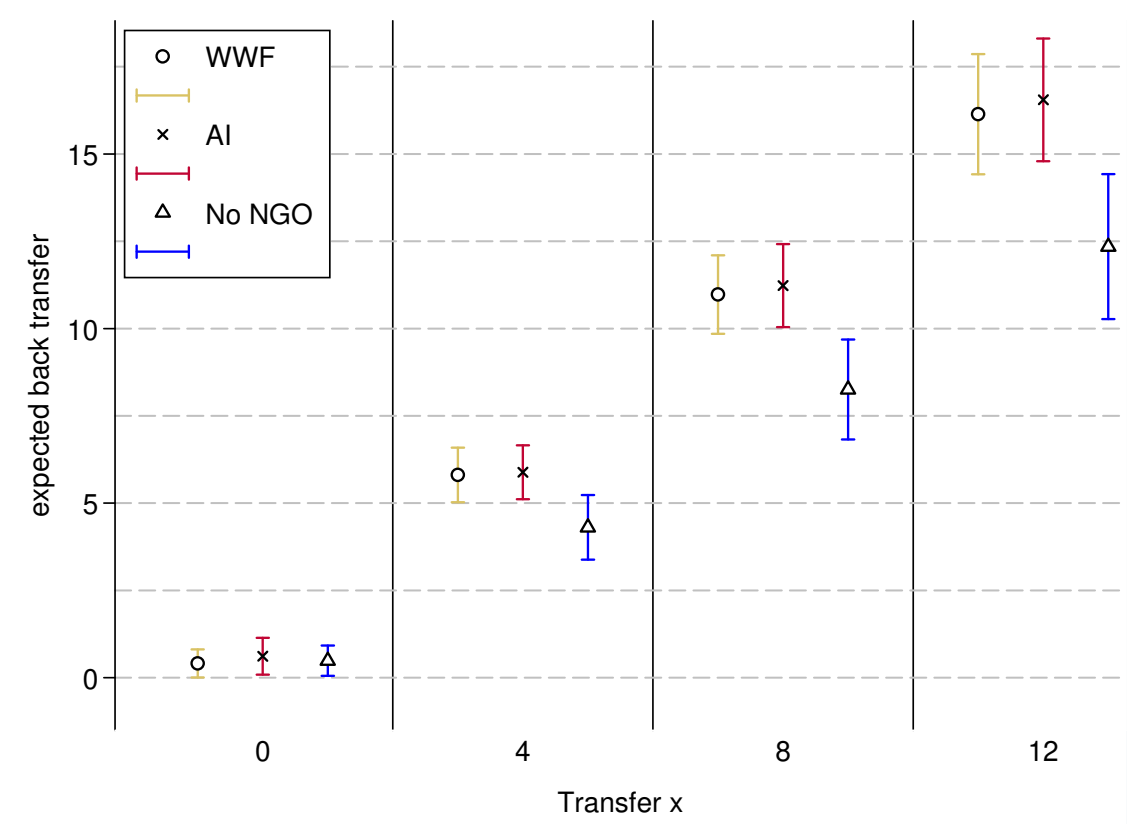

Note: Expected back transfers from different NGO types in the mission treatment (and their 95\% confidence intervals).

Table 1: Transfer levels from members of each group to all different trustees

\begin{tabular}{lcccc}
\hline Mission Treatment & & & & \\
& to WWF & to AI & to No-NGO & N \\
\hline from WWF & $8.3(0.8)$ & $7.9(0.8)$ & $4.6(0.9)$ & 28 \\
from AI & $7.1(1.2)$ & $8.3(1.2)$ & $4.6(1.8)$ & 14 \\
from No-NGO & $6.8(0.7)$ & $7.6(0.7)$ & $5.9(0.8)$ & 36 \\
\hline
\end{tabular}

\section{Minimal Group Treatment}

\begin{tabular}{lcccc} 
& to Klee & to Kandinski & to No-Artist & $\mathrm{N}$ \\
\hline from Klee & $8.6(1.0)$ & $6.6(1.1)$ & $6.4(1.1)$ & 22 \\
from Kandinski & $7.6(0.9)$ & $8.8(0.8)$ & $6.7(1.1)$ & 19 \\
from No-Artist & $6.3(1.0)$ & $6.2(1.0)$ & $8.3(0.9)$ & 26 \\
\hline \hline
\end{tabular}

Note: Standard errors in parentheses. 
on the NGO type of the trustor. This allows us to see whether the NGO types are more trustworthy when the group identity is unrelated to their NGO identification. In the minimal group treatment the transfers have to be conditioned on the art preferences of the trustor. As we used the same questionnaire for both the minimal group and mission treatments, we can group the results by the answers to the NGO question. Figure 2 presents the back transfers averaged over the three potential recipient types ("Klee", "Kandinski", and "No-Artist") for all potential transfers.

Figure 2: Average back transfers of different NGO types in the minimal group treatment

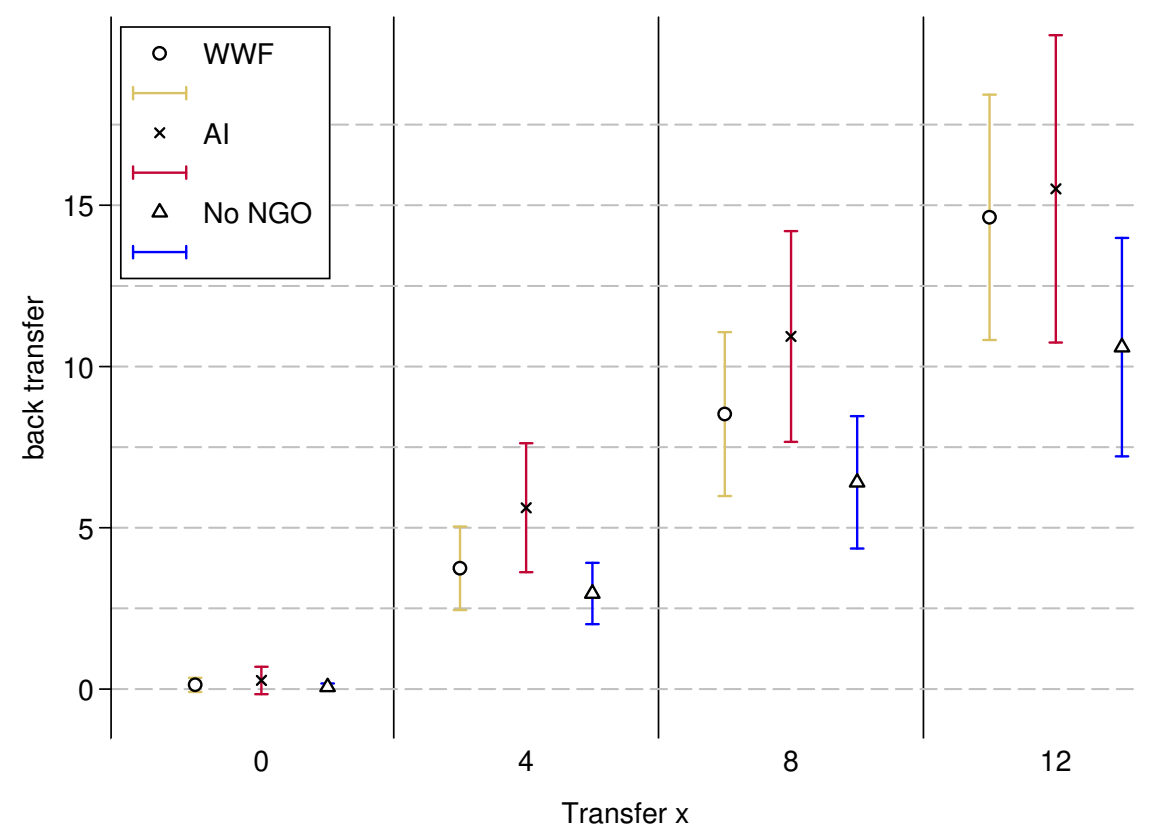

Note: The back transfers from the different NGO groups are averaged over the three recipient (artist) groups in the minimal group treatment. The intervals displayed are $95 \%$ confidence intervals.

We see that people who identify themselves with one of the NGOs are more trustworthy than people who do not. Regressing back transfer on transfer gives significantly different slopes for the AI group than for the No-NGO group $(\mathrm{p}<0.05$, F-Test, Regression 5, Table 2). ${ }^{6}$ Pooling the AI and the WWF group in the regression gives a significantly different slope of this combined NGO group to the No-NGO group slope $(\mathrm{p}<0.05$, F-Test, Regression 6 , Table 2). The slope of the WWF group alone is not significantly different to the slopes of the No-NGO group ( $\mathrm{p}>0.1$, Regression 5, Table 2) and the AI group ( $\mathrm{p}>0.1$ ).

\footnotetext{
${ }^{6}$ In this and following regressions there are four observations from every trustor (one for each possible transfer level). In the estimation of the standard errors these are, therefore, treated as one cluster each.
} 
Table 2: Regressions of expected back transfer and average back transfer on transfers from different groups

\begin{tabular}{|c|c|c|c|c|c|c|}
\hline & (1) & $\begin{array}{c}(2) \\
W W F\end{array}$ & $\begin{array}{l}(3) \\
\text { AI }\end{array}$ & $\begin{array}{c}(4) \\
\text { No NGO }\end{array}$ & $(5)$ & (6) \\
\hline & \multicolumn{6}{|c|}{$\begin{array}{l}\text { dependent variable: expected back transfers in models (1)-(4) } \\
\text { and back transfers in }(5)-(6)\end{array}$} \\
\hline wwf $[0,1]$ & $\begin{array}{l}0.48^{*} \\
(0.23)\end{array}$ & $\begin{array}{c}0.73 \\
(0.48)\end{array}$ & $\begin{array}{c}0.91 \\
(0.57)\end{array}$ & $\begin{array}{c}0.12 \\
(0.24)\end{array}$ & $\begin{array}{l}-0.49 \\
(0.26)\end{array}$ & \\
\hline ai $[0,1]$ & $\begin{array}{l}0.60^{*} \\
(0.28)\end{array}$ & $\begin{array}{c}0.52 \\
(0.46)\end{array}$ & $\begin{array}{c}1.31 \\
(0.82)\end{array}$ & $\begin{array}{c}0.38 \\
(0.39)\end{array}$ & $\begin{array}{c}0.43 \\
(0.29)\end{array}$ & \\
\hline no-ngo $[0,1]$ & $\begin{array}{c}0.42 \\
(0.24)\end{array}$ & $\begin{array}{c}0.28 \\
(0.34)\end{array}$ & $\begin{array}{c}0.16 \\
(0.21)\end{array}$ & $\begin{array}{c}0.63 \\
(0.43)\end{array}$ & $\begin{array}{l}-0.25 \\
(0.20)\end{array}$ & $\begin{array}{l}-0.25 \\
(0.20)\end{array}$ \\
\hline ngo $[0,1]$ & & & & & & $\begin{array}{l}-0.15 \\
(0.21)\end{array}$ \\
\hline transfer $\times w w f$ & $\begin{array}{l}1.31^{* * *} \\
(0.073)\end{array}$ & $\begin{array}{c}1.31^{* * *} \\
(0.11)\end{array}$ & $\begin{array}{c}1.19^{* * *} \\
(0.18)\end{array}$ & $\begin{array}{c}1.36^{* * *} \\
(0.12)\end{array}$ & $\begin{array}{c}1.21^{* * *} \\
(0.15)\end{array}$ & \\
\hline transfer $\times$ ai & $\begin{array}{l}1.33^{* * *} \\
(0.075)\end{array}$ & $\begin{array}{c}1.31^{* * *} \\
(0.13)\end{array}$ & $\begin{array}{c}1.28^{* * *} \\
(0.22)\end{array}$ & $\begin{array}{c}1.36^{* * *} \\
(0.10)\end{array}$ & $\begin{array}{c}1.28^{* * *} \\
(0.17)\end{array}$ & \\
\hline transfer $\times$ no-ngo & $\begin{array}{l}0.99^{* * *} \\
(0.080)\end{array}$ & $\begin{array}{c}0.94^{* * *} \\
(0.13)\end{array}$ & $\begin{array}{c}0.84^{* * *} \\
(0.16)\end{array}$ & $\begin{array}{c}1.08^{* * *} \\
(0.13)\end{array}$ & $\begin{array}{c}0.88^{* * *} \\
(0.14)\end{array}$ & $\begin{array}{c}0.88^{* * *} \\
(0.14)\end{array}$ \\
\hline transfer $\times$ ngo & & & & & & $\begin{array}{c}1.23^{* * *} \\
(0.12)\end{array}$ \\
\hline$N$ & 936 & 336 & 168 & 432 & 268 & 268 \\
\hline$R^{2}$ & 0.76 & 0.80 & 0.76 & 0.74 & 0.70 & 0.70 \\
\hline
\end{tabular}

Note: Standard errors in parentheses; ${ }^{*} p<0.05,{ }^{* *} p<0.01,{ }^{* * *} p<0.001$. In models (1)-(2) expected back transfer is regressed on the group dummies of the trustors and their transfers. Model (1) refers to Figure 1. In models (5) and (6) the dependent variable is the average back transfer to the three artist types. Model (5) refers to Figure 2. In model (6) both NGO groups are pooled. 
Figure 3: Trustworthiness of different trustee groups towards different trustor groups
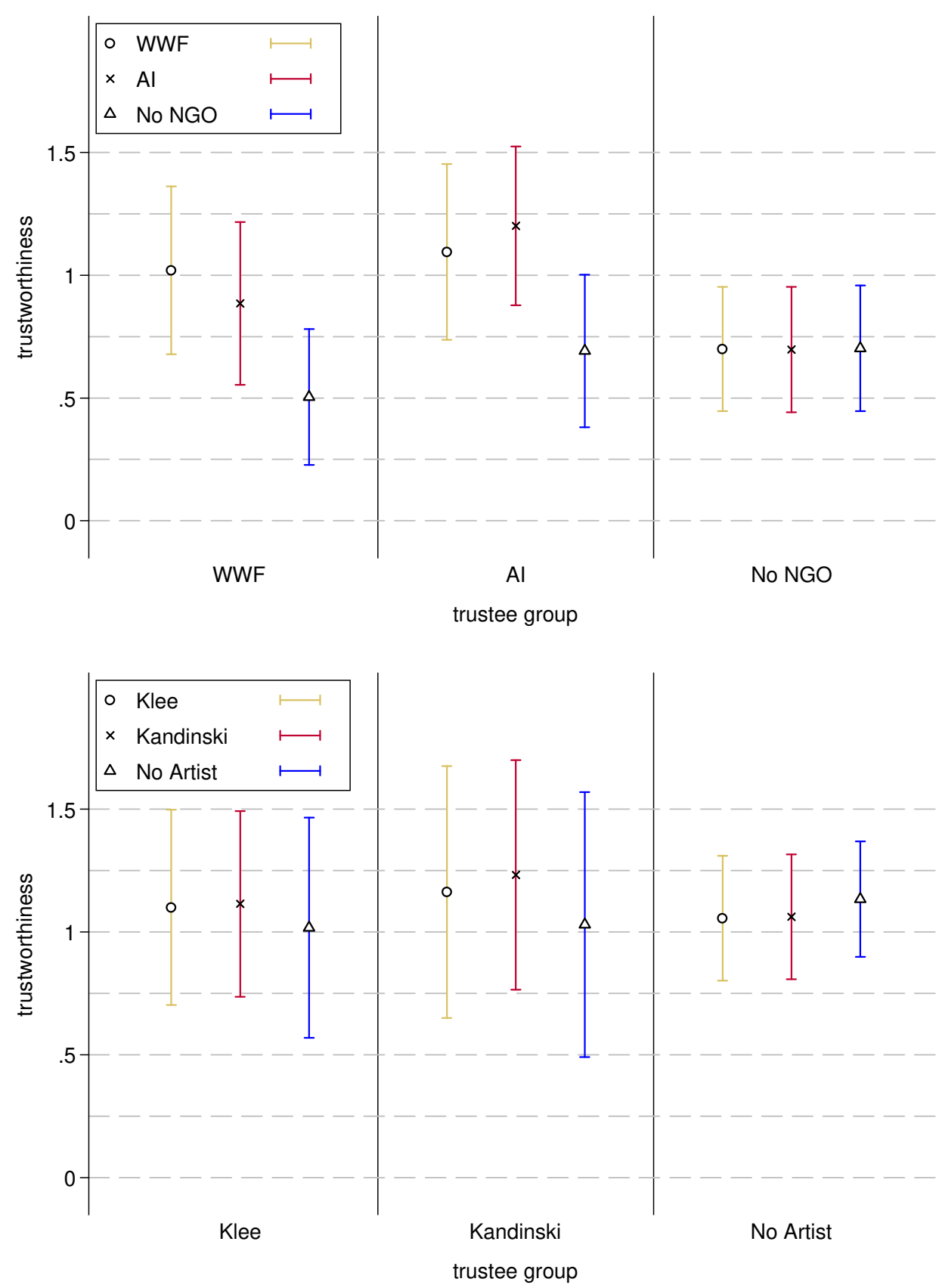

Note: Each panel displays the coefficients (and their 95\% confidence intervals) of regressions of back transfers from a different group of trustees on transfers from a different group of trustors. Full results from the regression models are reported in Table 3 . 
Next we study what happens if subjects are grouped by their NGO identification. Figure 3, which shows the estimated coefficients from regressing back transfers on transfers for the different groups, gives a clear picture. We see that the NGO types strongly discriminate against No-NGO types. Regressing back transfer on transfer by trustor type gives significantly different coefficients for AI and WWF types than from No-NGO types $(\mathrm{p}<0.05$, F-Test, Regressions 7 and 8, Table 3). It is also the case that WWF types favor other WWF types over AI types $(\mathrm{p}<0.05)$. This might be explained by the mere in-group effect which is present even when group formation is arbitrary as in the artist treatment. The lower half of Figure 3 shows that there are small differences between the slopes for the different artist types. These differences are small, though, compared to the difference between the NGO and the No-NGO group (Regressions 10-12, Table 3). All differences except for one (back transfers to Kandinski and to No-Artist from Kandinski trustees) are insignificant ( $\mathrm{p}>0.1$, F-tests). We also find that No-NGO types do not discriminate between the trustor groups (third panel in upper half of Figure 3 and Regression 9 in Table 3).

Table 3: Regressions of back transfers of different groups on transfers from different groups

\begin{tabular}{|c|c|c|c|c|c|c|c|}
\hline & (7) & (8) & \multicolumn{2}{|l|}{$(9)$} & (10) & (11) & (12) \\
\hline & WWF & AI & \multicolumn{2}{|l|}{ No NGO } & Klee & Kand. & No Art. \\
\hline & \multicolumn{7}{|c|}{ dependent variable in all models: back transfers } \\
\hline \multirow[t]{2}{*}{ wwf $[0,1]$} & 1.00 & -0.35 & -0.12 & klee $[0,1]$ & 0.58 & 0.0071 & -0.40 \\
\hline & $(0.56)$ & $(0.33)$ & $(0.17)$ & & $(0.47)$ & $(0.15)$ & $(0.24)$ \\
\hline \multirow[t]{2}{*}{ ai $[0,1]$} & 0.97 & -0.050 & -0.083 & kandinski $[0,1]$ & -0.041 & -0.21 & $-0.45^{*}$ \\
\hline & $(0.53)$ & $(0.32)$ & $(0.19)$ & & $(0.34)$ & $(0.20)$ & $(0.22)$ \\
\hline \multirow[t]{2}{*}{ no-ngo $[0,1]$} & 0.27 & 0.017 & -0.063 & no-artist $[0,1]$ & 0.012 & 0.050 & -0.41 \\
\hline & $(0.33)$ & $(0.17)$ & $(0.21)$ & & $(0.30)$ & $(0.14)$ & $(0.24)$ \\
\hline \multirow[t]{2}{*}{ transfer $\times$ wwf } & $1.02^{* * *}$ & $1.09^{* * *}$ & $0.70^{* * *}$ & transfer $\times$ klee & $1.10^{* * *}$ & $1.16^{* * *}$ & $1.06^{* * *}$ \\
\hline & $(0.17)$ & $(0.18)$ & $(0.13)$ & & $(0.19)$ & $(0.24)$ & $(0.13)$ \\
\hline \multirow[t]{2}{*}{ transfer $\times$ ai } & $0.88^{* * *}$ & $1.20^{* * *}$ & $0.70^{* * *}$ & transfer $\times$ kandinski & $1.11^{* * *}$ & $1.23^{* * *}$ & $1.06^{* * *}$ \\
\hline & $(0.16)$ & $(0.16)$ & $(0.13)$ & & $(0.18)$ & $(0.22)$ & $(0.13)$ \\
\hline \multirow[t]{2}{*}{ transfer $\times$ no-ngo } & $0.50^{* * *}$ & $0.69^{* * *}$ & $0.70^{* * *}$ & transfer $\times$ no-artist & $1.02^{* * *}$ & $1.03^{* *}$ & $1.13^{* * *}$ \\
\hline & $(0.14)$ & $(0.15)$ & $(0.13)$ & & $(0.21)$ & $(0.25)$ & $(0.12)$ \\
\hline$N$ & 344 & 348 & 524 & $N$ & 204 & 168 & 432 \\
\hline$R^{2}$ & 0.37 & 0.48 & 0.37 & $R^{2}$ & 0.65 & 0.65 & 0.69 \\
\hline
\end{tabular}

Note: Standard errors in parentheses; ${ }^{*} p<0.05,{ }^{* *} p<0.01,{ }^{* * *} p<0.001$. In models (7)-(9) back transfers from the different NGO groups are regressed on the group dummies of the trustors and their transfers. Model (7) refers to the upper left panel in Figure 3, model (8) to the upper middle panel and (9) to the upper right panel. In models (10)-(12) back transfers from the different artist groups are regressed on the group dummies of the trustors and their transfers. Model (10) refers to the lower left panel, model (11) to the lower middle panel and (12) to the lower right panel. 
The comparison of the behavior of the NGO types in the two treatments reveals a strong negative discrimination against out-groups and no positive discrimination of in-groups. A regression of back transfers from WWF or AI types on transfers from either group in the mission treatment and from trustors in the minimal group treatment (the three artist groups pooled), gives us four coefficients (Regressions 13 and 14, Table 4). The coefficient for a transfer from an artist type is statistically not different to the coefficients for a transfer from a WWF or from an AI type ( $\mathrm{p}>0.1$, F-tests). However, the slope coefficient for a transfer from a No-NGO type is significantly smaller than the slope coefficient for a transfer from an artist type $(\mathrm{p}<0.05, \mathrm{~F}$-test $)$. This suggests that negative discrimination of out-group subjects is the main driver of the differences in back transfers in the mission treatment.

Table 4: Regressions of back transfers from NGO types on transfers from different groups in both treatments

\begin{tabular}{lcc}
\hline \hline & $(13)$ & $(14)$ \\
& WWF & AI \\
& dep. variable: & back transfers \\
\hline wwf[0,1] & 1.00 & -0.35 \\
& $(0.57)$ & $(0.34)$ \\
ai[0,1] & 0.97 & -0.05 \\
no-ngo[0,1] & $(0.53)$ & $(0.32)$ \\
& 0.27 & 0.02 \\
art $[0,1]$ & $(0.33)$ & $(0.17)$ \\
transfer $\times$ wwf & -0.49 & 0.43 \\
transfer $\times$ ai & $(0.26)$ & $(0.29)$ \\
& $1.02^{* * *}$ & $1.09^{* * *}$ \\
transfer $\times$ no-ngo & $(0.17)$ & $(0.18)$ \\
& $0.88^{* * *}$ & $1.20^{* * *}$ \\
transfer $\times$ art $[$ avg $]$ & $(0.16)$ & $(0.16)$ \\
& $\left(0.50^{* * *}\right.$ & $0.69^{* * *}$ \\
$N$ & $(0.14)$ & $(0.15)$ \\
$R^{2}$ & 344 & $1.28^{* * *}$ \\
\hline \hline
\end{tabular}

Note: Standard errors in parentheses; ${ }^{*} p<0.05,{ }^{* *}$ $p<0.01,{ }^{* * *} p<0.001$. In the models (14) and (15) back transfers from AI and WWF types, respectively, in both treatments are the dependent variable. 


\section{Conclusion}

We find that subjects who identify themselves with non-profit missions are more trustworthy if they interact with somebody with the same mission or if they interact in a neutral setting in which they do not know the (potential) pro-social mission of their partner. Attracting such individuals might be beneficial for organizations in the non-profit sector and possibly explain different compensation schemes, such as fixed salaries, as compared to more performance based remuneration schemes in for-profit organizations (e.g., Ballou and Weisbrod 2003). However, when the group identity of the organization is salient and there is an out-group that does not share it, strong discrimination might result. Besley and Ghatak (2005) discuss possible detrimental effects on worker motivation if an organization hires a new principal who is not dedicated to the organization's mission. This would, for example, be the case if an NGO hires a financial expert who has gained no merits as an activist. Our results suggest that such a mission mismatch might also be detrimental for trust inside the organization. They also suggest that trust between groups with very different goals, e.g., between an environmental NGO and an industrial producer, might be very low. This would make cooperations between them, e.g., in the context of a corporate social responsibility program, difficult. It seems that strong identification with a good cause goes hand in hand with intolerance toward out-groups.

\section{References}

Ballou, J., And B. Weisbrod (2003): "Managerial rewards and the behavior of for-profit, governmental, and nonprofit organizations: evidence from the hospital industry," Journal of Public Economics, 87(9-10), 1895 - 1920.

Ben-Ner, A., B. P. McCall, M. Stephane, and H. Wang (2009): "Identity and in-group/out-group differentiation in work and giving behaviors: Experimental evidence," Journal of Economic Behavior \& Organization, 72(1), 153-170.

Berg, J., J. Dickhaut, and K. McCabe (1995): "Trust, Reciprocity, and Social History," Games and Economic Behavior, 10(1), 122-142.

Besley, T., and M. Ghatak (2005): "Competition and Incentives with Motivated Agents," American Economic Review, 95, 616-636.

Brekke, K. A., K. E. Hauge, J. T. Lind, and K. Nyborg (2011): "Playing with the good guys. A public good game with endogenous group formation," Journal of Public Economics, 95(9-10), 1111-1118.

Brekke, K. A., And K. NyborG (2010): "Selfish bakers, caring nurses? A model of work motivation," Journal of Economic Behavior $\&$ Organization, 75(3), 377-394. 
Brewer, M. B. (1979): "In-Group Bias in the minimal intergroup situation: A cognitivemotivational analysis," Psychological Bulletin, 86(2), 307-324.

CAsari, M., And T. N. CAson (2009): "The strategy method lowers measured trustworthy behavior," Economics Letters, 103(3), 157-159.

Charness, G., L. Rigotti, and A. Rustichini (2007): "Individual Behavior and Group Membership," American Economic Review, 97(4), 1340-1352.

Chen, Y., And S. X. Li (2009): "Group Identity and Social Preferences," American Economic Review, 99(1), 431-57.

DelfgaAuw, J., And R. Dur (2007): "Signaling and screening of workers' motivation," Journal of Economic Behavior \& Organization, 62(4), 605-624.

Fehrler, S., And M. Kosfeld (2012): "Pro-Social Missions and Worker Motivation: An Experimental Study," Discussion paper, Institute for the Study of Labor (IZA).

FischBACHER, U. (2007): "z-Tree: Zurich toolbox for ready-made economic experiments," Experimental Economics, 10(2), 171-178.

Hargreaves Heap, S. P., And D. J. Zizzo (2009): "The Value of Groups," American Economic Review, 99(1), 295-323.

Kosfeld, M., and F. A. von Siemens (2011): "Competition, cooperation, and corporate culture," The RAND Journal of Economics, 42(1), 23-43.

Lazear, E. P., U. Malmendier, And R. A. Weber (2012): "Sorting in Experiments with Application to Social Preferences," American Economic Journal: Applied Economics, $4(1), 136-163$.

Mullen, B., R. Brown, And C. Smith (1992): "Ingroup bias as a function of salience, relevance, and status: An integration," European Journal of Social Psychology, 22(2), $103-122$.

Tajfel, H., M. Billig, R. Bundy, and C. Flament (1971): "Social Categorization and intergroup behaviour," European Journal of Social Psychology, 1(2), 149-178.

Tsutsui, K., And D. Zizzo (2012): "Group Status, Minorities and Trust," Discussion paper, SSRN. 


\section{Appendix}

[Instructions to the Experiment]

[Instructions for trustors; instructions for trustees were the same with switched roles and are therefore omitted here]

\section{Experiment: General Information for Participant A}

You will now participate in a scientific experiment.

If you carefully read the following instructions, you can earn money. How much money you will earn depends on your decisions and decisions of other participants in the experiment. It is, therefore, important to read the instructions carefully.

Please, note that it is not permitted to communicate with other participants during the experiment. If you have questions, please, direct them at us.

At the beginning of the experiment all participants receive a show-up fee of 10 CHF. During the course of the experiment you can earn points in addition to that. All points you earn are converted into Swiss Francs at the end of the experiment. The exchange rate is:

\section{Point $=0.80$ CHF .}

At the end you receive the income you have earned during the experiment plus the $10 \mathrm{CHF}$ show-up fee in cash. You will be paid out in a separate room, so that no other participant can see how much you have earned. 


\section{The Experiment}

In this experiment there are always a participant A and participant B together in a group of two. No participant knows the identity of the participant who is in her group, that is, all decisions are made anonymously.

\section{You are participant $A$.}

At the beginning, participants $\mathrm{A}$ and $\mathrm{B}$ receive 12 points. You, as participant A, can then transfer 0 , 4, 8, or 12 points to B. This transfer is tripled. If you transfer 4 points, for example, B receives 12 points in addition to her endowment. If you transfer 12 points, for example, B receives 36 points.

After you have made your decision participant B can transfer back any amount out of the points he disposes of to you. If you do not transfer zero points, for example, B can transfer 0 to 12 points back to you. In case you transfer your whole endowment of 12 points, B can transfer back between 0 and 48 points back to you $(12 \times 3=36$ plus 12 points endowment). The backtransfer is not tripled, that is, you receive exactly the amount of points B transfers back.

The income of both participants is determined in dependence on your and B's decisions as follows:

\section{You, as participant $\mathrm{A}$, earn}

12 - Your transfer to B +Participant B's backtransfer to you.

\section{Participant B earns}

$12+3 \times$ Your transfer to B - B's backtransfer to you

For your transfer you can choose $0,4,8$ or 12 Punkte wählen. For the backtransfer B can choose any integer amount of points (maximally the total points (s)he disposes of). 


\section{WWF, Amnesty International or None of the two}

In this experiment you can make your transfer decision dependent on a certain information. Before the instructions were distributed all participants filled in a short questionnaire. Among other questions it contained a question regarding the identification with the goals of one of the NGOs WWF or Amnesty International. The answer options were WWF, Amnesty International or None of the two. The participant B you are matched with in this experiment has also answered this question. You can make your transfer decision dependent on B's answer.

This means that you you make a transfer decision for every possible answer of B. In total you make three decisisons. The decision screen looks as follows.

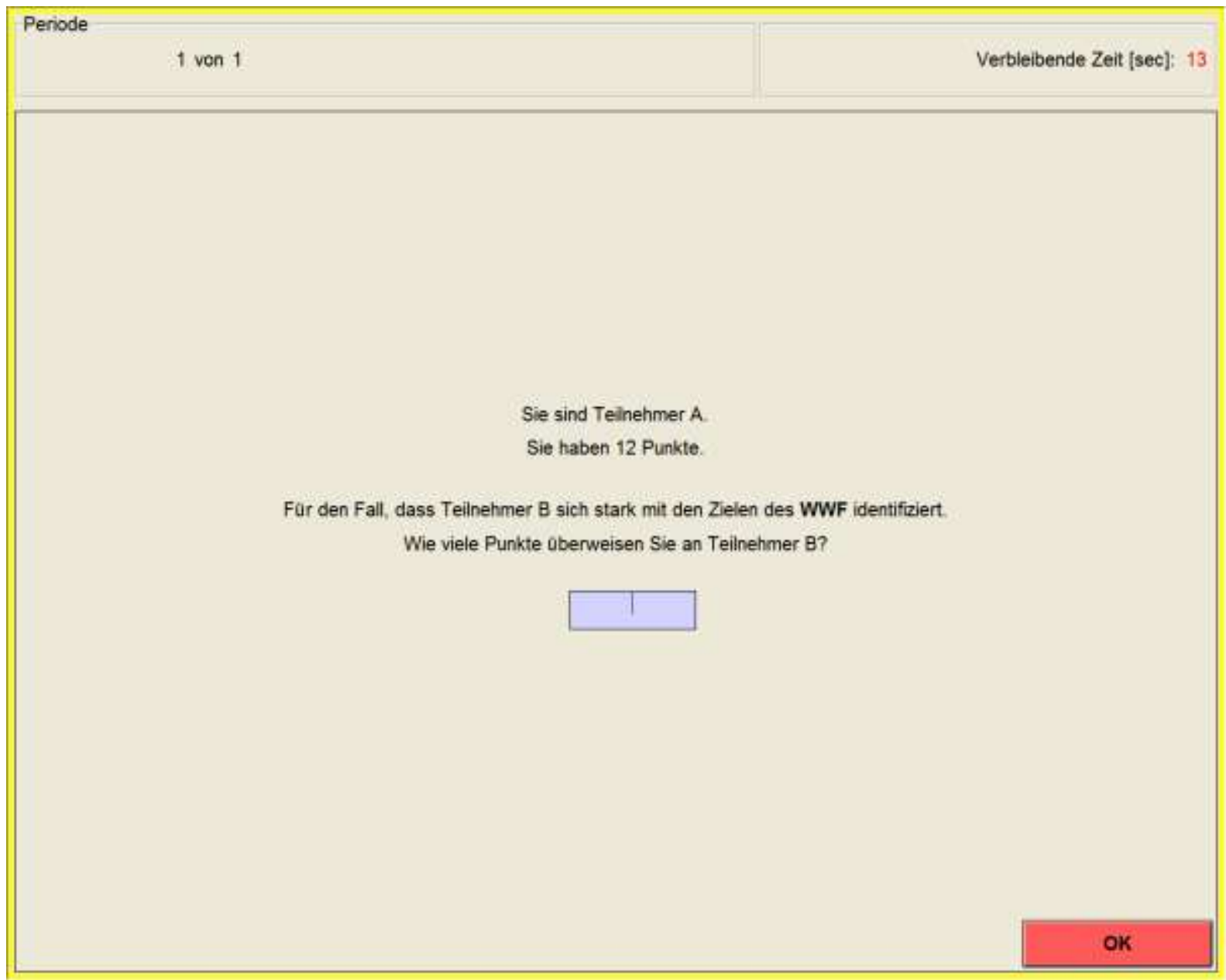

This screen displays the case that B has indicated that (s)he identifies her/himself strongly with the goals of the WWF. Please, enter your transfer for this case in the blue field. Please, confirm your decision by pressing the okay button. 
The other two screens for the case that B identifies her/himself strongly with the goals of Amnesty International and the case that (s)he does not strongly identify her/himself with either NGO look the same as the one above. The screen appear in random order.

Which of the three cases is relevant for your pay-off is determined by the actual answer of the participant $B$ you are matched with in the experiment. You will be informed about this decision after all participants have made their decisions.

Also participant B can make his/her backtransfer decisions to you dependent on how you have answered the question about the WWF and Amnesty International.

After all participants have made their transfer decisions, the expermint is over. You will then be informed how the particant B you are matched with has answered the question. The answer determines which of your transfer decisions is relevant. At the same time you are informed about B's backtransfer and the resulting pay-off to you. Your pay-off will then be paid out to you anonymously in cash, that is, the other participants do not get to know your pay-off.

\section{Control Questions}

Please, answer the following control questions. Your answers do not influence the pay-offs of the experiment but only serve to check whether everybody understands the experiment. When you have finished, please, raise your hand, so that we can check your answers.

Question 1: You are Participant A. How many transfer decisions are you going to make in this experiment?

Question 2: You are Participant A. What determines which of your decisions becomes relevant for the pay-offs?

Question 3: You are Participant A. Assume, your pay-off relevant transfer to B is 0 points, and Participant B's relevant backtransfer is also 0 points.

What is your income?

What is participant B's income? 
Question 4: You are Participant A. Assume, your pay-off relevant transfer to B is 12 points, and Participant B's relevant backtransfer is also 12 points.

What is your income?

What is participant B's income?

Question 5: You are Participant A. Assume, your pay-off relevant transfer to B is 8 points, and Participant B's relevant backtransfer is also 5 points.

What is your income?

What is participant B's income?

Do you have any questions? 